\title{
Bahasa nonverbal sebagai konteks dalam pembelajaran BIPA: kajian pragmatik edukasional
}

\author{
Pranowo *), \\ Guru Besar Program Studi Magister Pendidikan Bahasa dan Sastra Indonesia, FKIP, \\ Universitas Sanata Dharma Yogyakarta \\ *) Corresponding author: Jl. Affandi, Santren, Caturtunggal, Kec. Depok, Kabupaten Sleman, Daerah Istimewa Yogyakarta \\ 55281; Indonesia \\ e-mail: prof.pranowo2@gmail.com
}

\begin{abstract}
Non-verbal language learning as a context of Indonesian as foreign language learning needs serious attention because, in addition to learning verbal writing language, they also learn spoken language and cultural background. Therefore, learning must integrate an educationally linguistic approach with educational pragmatic words. Educational linguistic approaches in its nature are teaching the structure of language and its meaning, while a pragmatic approach or communicative approach is, in fact, the teaching of the use of languages and the context of its usage. The problem in this article is "What is the role of non-verbal language as a context in Indonesian language learning for foreign speakers (BIPA), an educational pragmatic study?". The purpose of this study is (1) to describe the use of nonverbal language as a context that often accompanies verbal language, (2) want to set the BN learning that is related to verbal based on a pragmatic approach, (3) want to Describe the pragmatic nature of Educational, (4) want to describe the process of acquisition of BIPA integrated between verbal language with non-verbal language, (5) want to describe the role of BIPA teacher.
\end{abstract}

Keywords: educational pragmatics, nonverbal language, context, communicative competence, BIPA.

\section{Pendahuluan}

Pembelajaran bahasa Indonesia untuk penutur asing (BIPA) perlu dicarikan solusi karea mereka tidak cukup hanya belajar bahasa Indonesia berdasarkan pendekatan linguistik seperti belajar bunyi, kata, kalimat, dan makna sebagai aspek intralingual. Mereka juga harus dibekali aspek ekstralingual berupa pendekatan pragmatik (seperti, konteks situasi, konteks sosial, kontek sosietal, dan konteks budaya), dan kompetensi komunikatif (kompetensi sosiolinguistik, kompetsi budaya, kompetensi strateik, dll.). Hal itu perlu mendapat perhatian karena pembelajar BIPA di samping belajar bahasa verbal, mereka juga harus belajar bahasa nonverbal. Karena, berkomunikasi tidak cukup hanya berbekal bahasa kata. Bahasa nonverbal adalah bahasa selain kata. Bahasa nonverbal dapat dibedakan menjadi dua, yaitu bahasa nonverbal dinamis dan bahasa nonverbal statis.

Pengintegrasian aspek intralingual dan ekstralingual dalam pembelajaran BIPA dapat meningkatkan kemampuan pembelajar dalam hal penguasaan bahasa Indonesia. Pembelajar BIPA di samping harus mempelajari bahasa tulis juga harus mempelajari bahasa lisan. Pembelajaran bahasa tulis dengan pendekatan linguistik edukasional mungkin sudah cukup memadai karena aspek ekstralingual dalam bahasa tulis sangat terbatas pada aspek tanda baca. Sementara itu, pembelajaran bahasa lisan, banyak aspek ekstralingual berupa bahasa nonverbal, konteks, maupun kompetensi komunikatif. Oleh karena itu, pembelajaran bahasa, di samping menggunakan pendekatan linguistik edukasional juga harus menggunakan pendekatan pragmatik edukasional. Hal ini karena ada tuntutan bahwa pembelajar harus menguasai bahasa Indonesia yang baik, benar, santun, dan akurat.

Seluruh proses pembelajaran bahasa yang dimaksud tergantung pada guru. Kehadiran guru ketika mengajar di kelas dengan bahasa verbal dan nonverbal ibarat guru sedang bermain orchestra musik. Jika 
kehadiran guru di kelas dapat menjadikan siswa belajar dengan penuh semangat dan dapat menikmati proses pembelajaran sehingga dengan mudah menangkap dan memahami maksud guru, itulah model pembelajaran yang diinginkan siswa (Karim \& Sotoudehnama, 2017). Dengan ungkapan perumpamaan seperti itu, guru dapat menjadi model belajar bagi pembelajar. Sebaliknya, jika bahasa verbal yang diiringi dengan bahasa nonverbal tidak sinkron, pembelajar akan sulit memahami apa yang dimaksud oleh guru. Kepercayaan siswa kepada guru tidak berkaitan dengan pengetahuan, pengalaman, tingkat pendidikan, atau posisi guru, tetapi bila murid percaya bahwa dia adalah seorang guru. BN siswa dapat dianggap sebagai tanda yang mencerminkan kepercayaan terhadap guru, semua itu akan berdampak pada kredibilitas dan kepercayaan siswa kepada guru.

Komunikasi nonverbal dapat dimanfaatkan untuk memeriksa apakah siswa mengerti, atau justru bingung. Dalam kondisi itu, BN siswa dengan cepat akan memberi tahu guru apa yang harus dilakukannya. Begitu juga, jika guru menonton siswa ketika siswa mendengarkan guru, terutama ketika guru sedang mencari tanda-tanda persepsi siswa terhadap pembelajaran guru akan nampak reaksi siswa terhadap guru, atau sebalikya. Dengan demikian, BN tidak hanya dianggap sebagai alat bagi guru untuk menyampaikan pesan tetapi juga sebagai sarana untuk menafsirkan pesan yang disampaikan oleh guru sehingga siswa dapat memahaami maksud melalui BN guru.

Pembelajar bahasa Indonesia bagi penutur asing (BIPA) pada umumnya memiliki motivasi instrumental. Mereka belajar bahasa Indonesia (BI) untuk keperluan tertentu, misalnya untuk mempelajari ilmu pengetahuan, teknologi, kebudayaan, dan bahkan untuk memperoleh pekerjaan, dll. Oleh karena itu, di samping harus menguasai bahasa verbal, mereka juga harus menguasai bahasa nonverbal. Namun, pembelajaran bahasa nonverbal (PBN) jarang mendapat porsi memadai dalam pembelajaran yang dilakukan oleh guru, instruktur, atau dosen bagi pembelajar BIPA.

Pendekatan pembelajaran BIPA selama ini terbatas pada pendekatan linguistik yang mengajarkan aspek intralingual (pelafalan bunyi, pembentukan kata, penyusunan kalimat, dan pemaknaan kata). Pembelajaran bahasa pada aspek ekstralingual belum banyak mendapat perhatian. Aspek ekstralingual yang dimaksud adalah PBN sebagai konteks dalam pendekatan pragmatik edukasional. Aspek bahasa yang dibahas dalam artikel ini adalah aspek ekstralingual berupa PBN. Pragmatik edukasional yang dimaksud dalam artikel ini adalah pembelajaran bahasa nonverbal bagi pembelajar bahasa Indonesia untuk penutur asing. Agar mendapatkan gambaran yang jelas, bagan berikut dapat menjelaskan maksud artikel ini.

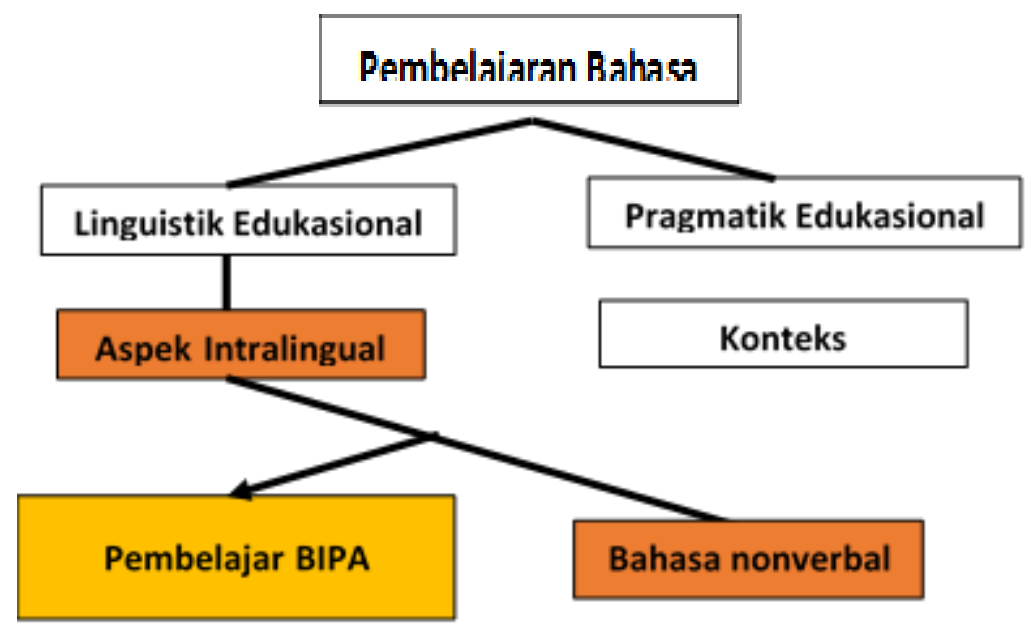

Berdasarkan bagan di atas, pembelajaran BIPA mencakup bahasa verbal dan bahasa nonverbal. Pembelajaran bahasa verbal tetap menggunakan pendekatan linguistik edukasional, sedangkan PBN menggunakan pendekatan pragmatik edukasional. Namun, pembelajaran BIPA harus mengintegrasikan antara pendekatan linguistik edukasional dengan pendekatan pragmatik edukasional. Dengan demikian, kedua pendekatan tersebut harus dilaksanakan secara simultan. Oleh karena itu, para guru atau pengajar 
74 Nonverbal language as a context in learning Indonesian as foreign language speakers: educational pragmatics study

BIPA perlu membuat rancangan pembelajaran yang mampu mengintegrasikan pendekatan linguistik edukasional dengan pragmatik edukasional.

BN dalam pembelajaran BIPA sebagai konteks bahasa verbal akan melengkapi pembelajaran dengan pendekatan linguistik. Berdasarkan uraian di atas, rumusan masalah dalam artikel ini adalah "Apaka peran bahasa nonverbal sebagai konteks dalam pembelajaran BIPA, suatu kajian pragmatk edukasional?".

\section{Metode}

Desain penelitian ini merupakan penelitian pustaka. Data dikumpulkan dengan teknik baca dan telaah untuk mendapatkan teori yang relevan dengan topik kajian. Teori yang dibaca dan ditelaah adalah bahasa nonverbal dalam komunikasi, (b) kondisi pembelajaran BIPA, pragmatik edukasional, peranan konteks, dan kompetensi komunikatif. Tujuan kajian ini adalah (1) ingin mendeskripsikan penggunaan bahasa nonverbal yang sering menyertai bahasa verbal, (2) ingin mendeskipsikan pembelajaran BN yang diitegrasikan dengan bahasa verbal berdasarkan pendekatan pragmatik, (3) ingin mendeskripsikan hakikat pragmatik edukasional, (4) ingin mendeskripsikan proses pemerolehan BIPA yang terintegrasi antara bahasa verbal dengan bahasa nonverbal, (5) ingin mendeskripsikan peranan guru BIPA. Teknik analisis data dilakukan dengan langkah-langkah sebagai berikut (1) identifikasi referensi, (2) klasifikasi referensi, (3) telaah referensi, dan (4) perumusan kesimpulan.

\section{Pembahasan}

\section{Bahasa Nonverbal dalam Pembelajaran BIPA}

Gerakan nonverbal tidak selalu dapat disebut sebagai bahasa nonverbal jika tidak ikut menentukan makna pragmatik. Hal itu mencakup gerakan BN statis maupun dinamis. BN statis dapat mencakup aspek di luar bagian tubuh. Kondisi strata sosial dalam masyarakat, jika ikut menyampaikan makna pragmatik penutur juga dapat dikategorikan sebagai $\mathrm{BN}$. Wujud $\mathrm{BN}$ statis adalah (a) bagian tubuh yang mengandung makna pragmatik, seperti postur tubuh, raut muka, warna kulit, warna rambut, dan lain-lain yang dimiliki oleh penutur (Botting, 2005), (Lapakko, 2007), (Zhou, X 2009), dan (b) status sosial, asal keturunan, tingkat kecerdasan dan persepsi mitra tutur terhadap kedudukan dalam masyarakat dapat membantu penafasiran makna pragmatik penutur (Pranowo, 2018).

BN dinamis adalah bahasa tubuh dan anggota tubuh disertai gerakannya, seperti kontak mata, gerakan anggota badan (seperti ekspresi wajah, gerakan mata, gerakan kepala, gerakan tangan, gerakan badan), atau kombinasi yang satu dengan yang lain untuk mengungkapkan makna pragmatik penutur. Penguasaan BN, baik statis maupun dinamis dapat dikategorikan sebagai kompetensi pragmatik. Jika pembelajar BIPA ingin menguasai bahasa Indonesia dengan baik, mereka harus menguasai BN sebagai salah satu kompetensi pragmatik. Kompetensi pragmatik yang dimaksud mencakup (a) kompetensi tatabahasa (pengetahuan fonologi, morfologi, sintaksis). Kompetensi ini sama dengan kompetensi linguistik yang dimaksud Chomskhy, (b) kompetensi sosiolinguistik yang dimaksud adalah pengetahuan penguasaan variasi bahasa atas dasar konteks sosial, (c) kompetensi wacana berkaitan dengan kemampuan menjaga kekohesiaan dan kekoherensian suatu wacana dalam berkomunikasi, dan (e) kompetensi strategis berkaitaan dengan petunjuk verbal dan non-verbal agar interaksi lebih efektif dan tidak menghambat komunikasi (Takkaç Tulgar, 2018).

Pembelajaran BIPA tidak hanya mengajarkan aspek intralingual yang berkaitan dengan pelafalan bunyi, pembentukan kata, penyusunan kalimat, dan pemaknaan kata. Aspek ekstralingual berupa BN sebagai konteks juga perlu diajarkan karena ikut menentukan makna pragmatik penutur. Jika BN ikut diajarkan dalam BIPA, pembelajar akan menguasai pemakaian bahasa secara akurat untuk menyampaikan pesan kepada pendengar sesuai dengan budaya masyarakat. Hal ini menjadi penting karena pembelajar BIPA belum cukup hanya menguasai bahasa tanpa menguasai budaya karena pembelajar BIPA akan berinteraksi dengan masyarakat pemilik budaya bahasa Indonesia.

Apa lagi, dengan perkembangan teknologi generasi 4.0, batas-batas wilayah suatu negara tinggal batas administratif. Setiap negara tidak dapat membatasi keluar-masuknya teknologi informasi, komunikasi, dan transportasi. Hal ini akan mempengaruhi dunia pendidikan pada umumnya, dan pembelajaran BIPA pada khususnya. Dengan demikian, pemerolehan bahasa nonverbal tidak dapat 
dikesampingkan dalam pembelajaran BIPA. Setiap orang asing yang berlajar BIPA, mereka akan bepergian dan berkomunikasi dengan semua masyarakat yang berlatar belakang sosial, situasi, sosietal, dan budaya yang berbeda-beda.

Berkaitan dengan minat belajar bahasa Indonesia, penutur asing yang ingin mempelajari bahasa Indonesia semakin berkembang sebagai akibat perkembangan teknologi komunikasi, informasi, dan transportasi. Salah satu faktor semakin tertariknya orang asing belajar BIPA adalah ketersediaan lapangan kerja di Indonesia. Indonesia banyak menggunakan teknologi asing yang masih membutuhkan tenaga kerja asing untuk pengoperasiannya.

Kehadiran tenaga kerja asing di Indonesia agar mudah diterima oleh masyarakat setempat hendaknya tidak sekedar mempelajari bahasa verbal. Di samping bahasa verbal, calon tenaga kerja asing hendaknya juga memahami aspek budaya masyarakat Indonesia. Salah satu aspek budaya sebagai konteks berbahasa adalah BN yang biasa menyertai bahasa verbal untuk memudahkan pengungkapan makna pragmatik penutur dan mempermudah pemahaman mitra tutur. Komunikasi nonverbal adalah sejenis komunikasi yang menggunakan cara apa pun selain bahasa verbal atau proses pengiriman dan penerimaan pesan tanpa menggunakan kata-kata (Karim \& Sotoudehnama, 2017).

\section{Pragmatik Edukasional sebagai Pendekatan Pragmatik}

Pragmatik edukasional adalah pendekatan pembelajaran bahasa berdasarkan pendekatan pragmatik. Pendekatan pragmatik yang dimaksud adalah pendekatan pembelajaran bahasa berdasarkan konteks. Wujud konteks yang dimaksud dapat berupa konteks situasi, konteks sosial, konteks sosietal, dan konteks budaya (Song, 2011). Keseluruhan konteks tersebut diimpelementasikan dalam pembelajaran bahasa. Aspek pragmatik yang memanfaatkan konteks dalam tindak tutur lisan biasanya tidak diwujudkan dalam bentuk bahasa verbal tetapi diwujudkan dalam bentuk BN.

Jika BN dipergunakan dalam proses pembelajaran bahasa di kelas akan dapat membantu memecahkan beberapa masalah. Ketika isyarat nonverbal digunakan secara efektif dalam praktik di kelas, BN memberikan dukungan ekstra dalam proses pembelajaran, seperti (1) mengurangi waktu bicara guru yang tidak perlu, (2) membangkitkan partisipasi peserta didik, (3) membangun kepercayaan pada diri siswa, (4) mengurangi rasa takut akan kesunyian, (5) memberikan instruksi yang jelas, (6) mengelola kelas secara efisien, (7) mengembangkan keterampilan mendengarkan.

Bahasa nonverbal (BN) adalah bahasa selain kata. Wujud BN berupa bagian tubuh beserta gerakannya, atau bagian tubuh lain yang ikut menentukan makna pragmatik penutur. Bahkan, strata sosial seseorang di dalam masyarakat pun dapat disebut sebagai BN jika ikut menentukan makna pragmatik penutur. Makna pragmatik strata sosial biasanya diinterpretasi oleh mitra tutur. Sebaliknya, bagian tubuh beserta gerakannya tidak selalu dapat disebut bahasa nonverbal, jika tidak ikut menentukan makna pragmatiknya. Misalnya, orang mengerdipkan mata karena kemasukan debu tidak dapat disebut sebagai bahasa nonverbal. Orang berjalan dengan melangkahkan kaki dan melambaikan tangan tidak dapat disebut sebagai bahasa nonverbal jika tidak ikut menentukan makna pragmatik penutur. Gerakan nonverbal agar dapat disebut sebagai bahasa nonverbal harus memenuhi dua syarat, yaitu (a) gerakan itu harus dikaitkan dengan makna pragmatik, dan (b) gerakan itu disengaja oleh penutur dan harus dapat dipahami oleh mitra tutur (Zhou, H. (2009).

Komunikasi nonverbal merupakan bagian penting dari percakapan sehari-hari dan karena itu dapat menempati posisi penting dalam pengajaran bahasa kedua/ asing. BN dapat membantu peserta didik dalam belajar bahasa, baik dalam keterampilan berbicara maupun menyimak. Ada beberapa wujud BN yang sering muncul dalam proses pembelajaran (Negi, 1970), yaitu (1) proxemics (ruang antara komunikator), meliputi keakraban hubungan, sosial, ruang pribadi dan publik. Jarak antara dua orang yang berkomunikasi membantu mitra tutur untuk memahami jenis hubungan apa yang mereka miliki, (2) oculecsics (kontak mata), (3) haptics (perilaku menyentuh, seperti kontak fisik dengan seseorang: berjabat tangan, menepuk pundak, dll.), (4) kronologis (mengacu pada penggunaan waktu dan ketepatan waktu dalam komunikasi), (5) paralinguistic/vocalics: terkait dengan bagian pendengaran bicara, termasuk nada, intonasi, dan jeda pengucapan, (6) olfactics (berkaitan dengan bau dan kebersihan tubuh selama komunikasi antarpribadi) (Negi, 1970), dan (7) penampilan fisik (daya tarik personal, tinggi badan, berat tubuh, gaya rambut, warna kulit, dll.) (Abrahamsen et al., 2015). 
76 Nonverbal language as a context in learning Indonesian as foreign language speakers: educational pragmatics study

Komunikasi nonverbal mampu meningkatkan kualitas pembelajaran. Dengan komunikasi nonverbal, BN akan membantu guru untuk mendapatkan perhatian siswa dengan mudah daripada dengan komunikasi verbal dan pengetahuan materi pelajaran. $\mathrm{BN}$ dapat mendorong partisipasi siswa dan perhatian pada pelajaran (Fandohan et al., 2015). Oleh karena itu, sebagian besar pesan yang disampaikan akan memiliki akar dalam sistem komunikasi nonverbal. Komunikasi nonverbal berada di luar sistem bahasa tetapi memainkan peran penting dalam interaksi sosial manusia (Franco \& Galvis, 2014).

Hampir semua ahli sepakat - meskipun dengan perspektif yang berbeda-beda - bahwa sebagian besar komunikasi lisan disampaikan melalui bahasa nonverbal. Pertama, Birdwhistell mengklaim bahwa $65 \%$ makna pragmatik dalam komunikasi lisan disampaikan melalui bahasa nonverbal (Birdwhistell, 1970). Meskipun demikian, masih banyak orang yang belum menyadari bahwa komunikasi lisan disampaikan melalui bahasa nonverbal (Lakin, 2006). Kedua,Krauss, Chen, \& Chawla, (1996) memperkirakan lebih dari $82 \%$ untuk teknik komunikasi yang digunakan oleh guru di kelas adalah nonverbal. Ketiga, ada peneliti lain yang mengklaim bahwa komunikasi di kelas $90 \%$ menggunakan bahasa nonverbal. Dan keempat, Lapako menyatakan bahwa penggunaan BN dalam komunikasi lisan mencapai 93\% dari keseluruhan pemakaian bahasa verbal lisan (Lapakko, 2007). Yang ingin saya tekankan disini adalah bahwa peranan BN dalam komunkasi lisan sangat penting.

\section{Bahasa Nonverbal (BN) sebagai Konteks dalam Berkomunikasi}

Pemakaian BN diwujudkan menjadi konteks dalam berkomunikasi. Konteks dalam berkomunikasi dapat berupa konteks situasi, konteks sosial, konteks sosietal, dan konteks budaya (Hu, 2014). Pertama, konteks situasi adalah segala keadaan yang menggambarkan peristiwa tutur sehingga memperjelas makna pragmatik yang dimaksud oleh penutur. Misalnya, ketika peristiwa tutur sedang terjadi, tiba-tiba tuturan terhenti, penutur menanyakan "foto di dinding itu foto Bapak tahun berapa, kok seperti foto keluarga?". Pertanyaan itu memecahkan keheningan dan kemudian mitra tutur menjawab bahwa foto itu memang foto keluarga ketika istri masih hidup dan anak-anak masih kecil. Sambil menjelaskan foto, mitra tutur meneteskan air mata teringat peristiwa masa lalu ketika istrinya sakit dan kemudian meninggal, sementara anak-anak masih kecil. Tuturan itulah itulah yang disebut konteks situasi.

Kedua, konteks sosial yaitu konteks yang menyertai tuturan berdasarkan kondisi masyarakat. Konteks sosial merupakan lingkungan nonlinguistik ujaran yang merupakan alat untuk memerinci ciri-ciri situasi yang diperlukan untuk memahami makna pragmatik tuturan. Misalnya, seseorang yang berasal dari Malang Jawa Timur menanyakan "Kon wis mari, tah?" (Kowe wis rampung, pa?)". Dalam bahasa Jawa kata "mari" berarti "sembuh", sementara itu orang Malang, arti kata "mari" adalah "rampung: selesai". Dengan demikian, kalimat di atas yang dimaksud adalah pertanyaan "Kamu sudah selesai, kah?". Tuturan seperti itu merupakan tuturan khas Malang yang tidak pernah akan terjadi pada masyarakat lain. Tuturan seperti itu hanya mungkin dituturkan kepada teman sejawat, meskipun berasal dari masyarakat yang berasal dari daerah lain. Dengan demikian, konteks sosial di samping berdimensi horizontal dapat pula berdimensi dialek geografis.

Ketiga, konteks societal adalah konteks yang menjadi faktor penentu kedudukan seseorang dalam strata sosial masyarakat. Hal ini menunjukkan bahwa munculnya konteks sosietal adalah adanya kekuasaan (power), sedangkan dasar dari kemunculan konteks sosietal itu adalah adanya solidaritas (solidarity) (Rahardi, 2009). Kedudukan seseorang di dalam masyarakat akan memberi perspektif tertentu pada orang lain. Tuturan "orang itu memang memiliki tingkat kepekaan sosial tinggi". Tuturan seperti itu dituturkan oleh seorang Bupati kepada rakyatnya akan memiliki perspektif yang berbeda bila yang menuturkan seorang tukang kebun kepada teman-temannya. Tuturan Bupati kepada seluruh rakyatnya merupakan dimensi vertikal karena adanya power yang dimiliki oleh Bupati. Sementara tuturan tukang kebun lebih berdimensi horizontak dan tidak memiliki power apa-apa.

Keempat, konteks budaya yaitu konteks tuturan yang berkaitan dengan latar belakang budaya suatu masyarakat. Masyarakat Yogyakarta ketika mengadakan upacara adat pernikahan, mereka mengenakan baju "surjan", sementara masyarakat Surakarta mengenakan baju "beskap". Budaya berpakaian seperti itu juga termasuk kelengkapan busana lain. Misalnya, seorang pria atau wanita mengenakan kain batik, lipatan kain bagi wanita atau pria gaya Surakarta batas tepi kain batik yang biasanya berwarna beda dengan keseluruhan warna kain, ketika dipakai justru dilipat dan tertutup. Sementara itu, lipatan tepi kain untuk masyarakat Yogyakarta, lipatan tepi kain justru dinampakkan. Hal seperti itu merupakan budaya tradisi masyarakat yang berbeda-beda. Konteks budaya masyarakat yang berbeda-beda seperti itu, guru BIPA 
seharusnya mengajarkan kepada murid-muridnya agar mereka memahami aspek bahasa nonverbal budaya masyarakat tempat mereka belajar. Begitu juga ketika bertutur. Ketika penutur bertanya kepada mitra tutur, misalnya "apa perbedaan persepsi dengan perspektif, ya?", kemudian mitra tutur menjawab. Setelah mendapat jawaban dari penutur, mitra tutur mengatakan "terimakasih, ya". Dari aspek budaya, ucapan terimakasih seperti itu dapat disebut sebagai konteks budaya.

\section{BN sebagai Kompetensi Pragmatik dalam Pembelajaran Bahasa}

Di samping pembelajaran bahasa harus memperhatikan konteks, juga harus memperhatikan kompetensi pragmatik. Tuma \& Pratt mengidentifikasi kompetensi pragmatik sebagai salah satu elemen kompetensi komunikatif, menempatkan kompetensi pragmatik sebagai bagian dari kompetensi ilokusi, yang merupakan kombinasi antara tindak tutur dan fungsi bicara bersamaan dengan penggunaan bahasa yang tepat dalam konteks (Tuma, J. M., \& Pratt, J. M., 1982).

Thomas mendefinisikan kompetensi pragmatis sebagai "... kemampuan untuk menganalisis bahasa secara sadar" (Holmes \& Brown, 2007: 524). Kompetensi pragmatik mengacu pada kemampuan untuk memahami, membangun ucapan yang akurat dan sesuai dengan kebutuhan. keadaan sosial dan budaya di mana komunikasi terjadi. Kompetensi pragmatik harus menjadi tujuan utama bagi semua orang yang mengajarkan bahasa Indoneia sebagai bahasa kedua, yang sekaligus merupakan tugas yang menantang.

Dalam konteks berkomunikasi, seorang ahli pragmatik mengklasifikasikan bermacam-macam kompetensi, yaitu (a) kompetensi sosiolinguistik, (b) kompetensi interaksional, (c) kompetensi kultural, (d) kompetensi komunikatif, (e) kompetensi strategis, (f) kompetensi wacana, dan (g) komepetensi pragmatik (Deda, 2013: 65-67); (Takkaç Tulgar, 2018).

Dari sekian banyak kompetensi, salah satu kompetensi yang menarik adalah kompetensi pragmatik. Kompetensi pragmatik mengacu pada kemampuan untuk memahami, membangun, dan menyampaikan makna secara akurat sesuai dengan keadaan sosial dan budaya masyarakat tempat terjadinya komunikasi. Meskipun demikian, kompetensi satu dengan kompetensi lain sebenarnya berkaitan dengan kompetensi pragmatik. Misanya, keterkaitan kompetensi pragmatik dengan kompetensi sosiolinguistik.

Kompetensi sosiolinguistik merupakan kemampuan menafsirkan makna sosial dari unsur-unsur bahasa yang berkaitan dengan peristiwa komunikasi. Hal ini hanya dapat dilakukan jika penutur maupun mitra tutur memiliki pemahaman terhadap aturan sosial budaya yang biasa dipakai dalam berkomunikasi. Begitu juga dengan kompetensi budaya. Pengetahuan kompetensi budaya diperoleh secara sosial dalam arti pengetahuan yang dimiliki seseorang karena menjadi bagian dari anggota masyarakat tertentu. Pengetahuan dan perilaku sosial seseorang sangat ditentukan oleh lingkungan budaya masyarakat dimana mereka tinggal. Hal seperti itulah keterkaitan antara kompetensi pragmatik dengan kompetensi yang lain.

Berkaitan dengan pendekatan pragmatik edukasional, BN merupakan salah satu kompetensi pragmatik. Oleh karena itu, jika BN tidak diberi porsi penting dalam pembelajaran BIPA, kompetensi pragmatik pembelajar belum cukup memadai. Hal lain yang perlu diperhatikan berkaitan dengan pembelajaran bahasa, ketika guru berkomunikasi dengan siswa di kelas yang penting "bukan apa yang dikatakan, tetapi bagaimana cara mengatakannya" yang dapat membuat guru dipercaya siswa (Botting, 2005). Pada umumya, komunikasi nonverbal guru di kelas dapat mengompensasi bahasa verbal sehingga makna pragmatik dapat dipahami oleh pembelajar dengan jelas. Berdasarkan pernyataan di atas ada hal penting penerapan $\mathrm{BN}$ dalam komunukasi, yaitu (a) BN merupakan akar bahasa dalam komunikasi, (b) bahasa lisan sebagian besar menggunakan BN, (b) BN dapat mengompensasi bahasa verbal sehingga makna pragmatik dapat dipahami pembelajar dengan jelas.

Gerakan nonverbal tidak selalu dapat disebut sebagai bahasa nonverbal jika tidak ikut menentukan makna pragmatik. Hal itu mencakup gerakan BN statis maupun dinamis. BN statis dapat mencakup aspek di luar bagian tubuh. Kondisi strata sosial dalam masyarakat, jika ikut menyampaikan makna pragmatik penutur juga dapat dikategorikan sebagai BN. Wujud BN statis adalah (a) bagian tubuh yang mengandung makna pragmatik, seperti postur tubuh, raut muka, warna kulit, warna rambut, dan lain-lain yang dimiliki oleh penutur (Botting, 2005), (Lapakko, 2007), (Zhou, X 2009), dan (b) status sosial, asal keturunan, tingkat kecerdasan dan persepsi mitra tutur terhadap kedudukan dalam masyarakat dapat membantu penafasiran makna pragmatik penutur (Pranowo, 2018). 
78 Nonverbal language as a context in learning Indonesian as foreign language speakers: educational pragmatics study

BN dinamis adalah bahasa tubuh dan anggota tubuh disertai gerakannya, seperti kontak mata, gerakan anggota badan (seperti ekspresi wajah, gerakan mata, gerakan kepala, gerakan tangan, gerakan badan), atau kombinasi yang satu dengan yang lain untuk mengungkapkan makna pragmatik penutur. Penguasaan BN, baik statis maupun dinamis dapat dikategorikan sebagai kompetensi pragmatik. Jika pembelajar BIPA ingin menguasai bahasa Indonesia dengan baik, mereka harus menguasai BN sebagai salah satu kompetensi pragmatik. Kompetensi pragmatik yang dimaksud mencakup (a) kompetensi tatabahasa (pengetahuan fonologi, morfologi, sintaksis). Kompetensi ini sama dengan kompetensi linguistik yang dimaksud Chomskhy, (b) kompetensi sosiolinguistik yang dimaksud adalah pengetahuan penguasaan variasi bahasa atas dasar konteks sosial, (c) kompetensi wacana berkaitan dengan kemampuan menjaga kekohesiaan dan kekoherensian suatu wacana dalam berkomunikasi, dan (e) kompetensi strategis berkaitaan dengan petunjuk verbal dan non-verbal agar interaksi lebih efektif dan tidak menghambat komunikasi (Takkaç Tulgar, 2018).

Pembelajaran BIPA tidak hanya mengajarkan aspek intralingual yang berkaitan dengan pelafalan bunyi, pembentukan kata, penyusunan kalimat, dan pemaknaan kata. Aspek ekstralingual berupa BN sebagai konteks juga perlu diajarkan karena ikut menentukan makna pragmatik penutur. Jika BN ikut diajarkan dalam BIPA, pembelajar akan menguasai pemakaian bahasa secara akurat untuk menyampaikan pesan kepada pendengar sesuai dengan budaya masyarakat. Hal ini menjadi penting karena pembelajar BIPA belum cukup hanya menguasai bahasa tanpa menguasai budaya karena pembelajar BIPA akan berinteraksi dengan masyarakat pemilik budaya bahasa Indonesia.

Apa lagi, dengan perkembangan teknologi generasi 4.0, batas-batas wilayah suatu negara tinggal batas administratif. Setiap negara tidak dapat membatasi keluar-masuknya teknologi informasi, komunikasi, dan transportasi. Hal ini akan mempengaruhi dunia pendidikan pada umumnya, dan pembelajaran BIPA pada khususnya. Dengan demikian, pemerolehan bahasa nonverbal tidak dapat dikesampingkan dalam pembelajaran BIPA. Setiap orang asing yang berlajar BIPA, mereka akan bepergian dan berkomunikasi dengan semua masyarakat yang berlatar belakang sosial, situasi, sosietal, dan budaya yang berbeda-beda.

Berkaitan dengan minat belajar bahasa Indonesia, penutur asing yang ingin mempelajari bahasa Indonesia semakin berkembang sebagai akibat perkembangan teknologi komunikasi, informasi, dan transportasi. Salah satu faktor semakin tertariknya orang asing belajar BIPA adalah ketersediaan lapangan kerja di Indonesia. Indonesia banyak menggunakan teknologi asing yang masih membutuhkan tenaga kerja asing untuk pengoperasiannya.

Kehadiran tenaga kerja asing di Indonesia agar mudah diterima oleh masyarakat setempat hendaknya tidak sekedar mempelajari bahasa verbal. Di samping bahasa verbal, calon tenaga kerja asing hendaknya juga memahami aspek budaya masyarakat Indonesia. Salah satu aspek budaya sebagai konteks berbahasa adalah BN yang biasa menyertai bahasa verbal untuk memudahkan pengungkapan makna pragmatik penutur dan mempermudah pemahaman mitra tutur. Komunikasi nonverbal adalah sejenis komunikasi yang menggunakan cara apa pun selain bahasa verbal atau proses pengiriman dan penerimaan pesan tanpa menggunakan kata-kata (Karim \& Sotoudehnama, 2017).

\section{Proses Pemerolehan BI bagi Penutur Asing}

Dalam kaitan dengan pembelajaran BN, pemerolehan bahasa asing bagi orang dewasa terjadi melalui proses formal di kelas/sekolah. Berdasarkan teori monitor (Krashen, 2013) menyatakan bahwa proses penguasaan bahasa pertama dengan bahasa kedua/bahasa asing dibedakan secara tegas. Penguasaan bahasa pertama terjadi secara alamiah melalui proses pemerolehan dan penguasaan bahasa kedua/ bahasa asing terjadi secara formal di kelas/sekolah melalui proses pembelajaran. Teori Krashen itu masih menjadi perdebatan, namun sampai sekarang masih tetap dijadikan acuan utama para peneliti pemerolehan bahasa pertama maupun bahasa kedua/asing.

Meskipun teori Krashen sudah begitu berpengaruh, salah satu aspek penting yang belum diajarkan adalah proses pembelajaran BN. Padahal, penggunaan BN dalam komunikasi lisan mencapai sekitar 93\% dari keseluruhan pemakaian bahasa verbal lisan (Lapakko, 2007). Hal ini perlu mendapat perhatian para ahli pembelajaran BIPA. Setiap proses penguasan bahasa (baik melalui pemerolehan maupun pembelajaran) pasti melibatkan $\mathrm{BN}$.

Di tengah-tengah perkembangan teknologi generasi 4.0 perubahan berpikir seseorang dipengaruhi oleh perkembangan teknologi, terutama teknologi komunikasi, transportasi, dan informasi yang cukup 
signifikan. Sebagai dampak perkembangan teknologi, hampir setiap generasi muda sangat akrab dengan dunia internet yang menyebar luas di berbagai peralatan (seperti Gadget dan Laptop) dalam bentuk aplikasi software yang memberi berbagai kemudahan. Pembelajar BIPA dalam mendisain media pembelajaran seharusnya, di samping kata-kata verbal juga dapat menampilkan aktivitas nonberbal melalui media pembelajaran.

Oleh karena itu, guru BIPA harus berkreasi mengembangkan model pembelajaran berbasis teknologi digital agar mereka lebih mudah memperkaya kosakata, struktur kalimat, bahkan sampai makna pragmatik. Namun, pengembangan model pembelajaran BIPA tidak sekedar mengaplikasikan perangkat lunak yang sudah ada. Guru BIPA harus mampu menciptakan model media pembelajaran baru yang kreatif dan inovatif dengan menampilkan berbagai wujud BN.

Aspek penting pengintegrasian BN dalam pembelajaran BIPA adalah pemilihan strategi pembelajaran yang memberikan peluang pada aktivitas belajar pembelajar. Karim \& Sotoudehnama (2017) menyatakan bahwa seorang guru itu diibartkan sebagai komposer dan conductor. Seorang composer, guru dapat menyatukan unsur-unsur kalimat dengan cara membuat makna pragmatiknya jelas dan mudah diingat. Berbagai ekspresi wajah guru dapat berperan sebagai catatan dalam musik. Setiap nada memiliki suara yang berbeda sama seperti setiap ekspresi wajah ketika menyampaikan makna yang berbeda dalam bertutur. Ekspresi wajah sebagai salah satu aspek BN dapat digunakan untuk menjelaskan makna pragmatik yang dapat menghidupkan setiap tuturan di kelas. Ekspresi wajah membantu untuk memahami dan mempelajari kata-kata dan konsep. Berbagai ekspresi wajah guru dalam situasi yang berbeda dapat menciptakan suasana kelas sealamiah mungkin.

Pembelajar bahasa yang sukses memiliki karakteristik nyata dan mereka juga sangat termotivasi untuk belajar. Dengan model strategi seperti itu, pembelajar akan mudah bergaul, menjadi pekerja keras, dan berani mencoba-coba dan tidak takut berbuat salah ketika belajar. Mereka mampu menerapkan semua faktor dalam pembelajaran bahasa. Mereka mampu mengidentifikasi teman yang belajar dengan berhasil dan mereka yang kurang berhasil. Pembelajar dapat diamati, apakah cara mereka belajar sudah benar, dan apakah mereka telah mampu mengontrol strategi belajar mereka sendiri.

Guru yang diidealkan pembelajar adalah jika guru memiliki keterampilan untuk berkomunikasi secara efektif karena dianggap sebagai salah satu penentu penting keberhasilan belajar siswa. Guru tidak hanya dituntut untuk efektif dalam kegiatan belajar mengajar (transfer of knowledge), guru diharapkan menjadi model transfer sikap dan nilai-nilai, baik untuk pembelajar maupun semua anggota komunitas sekolah.

Dalam pembelajaran BIPA, bahasa verbal lisan tidak dapat dipisahkan dengan BN. Jika diamati secara cermat, setiap ucapan guru pasti disertai dengan BN. Gerakan tangan, perubahan raut muka, tatapan mata, bahkan penampilan guru di kelas (pakaian, make up, bau keringat, posisi berdiri) akan mempengaruhi pemahaman siswa terhadap makna pragmatik yang disampaikan oleh guru.

Guru di kelas ibarat seorang aktor di panggung. Semua ucapan dengan gerakan harus terkoordinasi secara baik agar pembelajar mampu memahami makna pragmatik yang ingin disampaikan oleh guru. Ucapan guru di kelas harus diatur secara teliti melalui persiapan mengajar (rancangan perkuliahan/pembelajaran "RPP"). Seorang guru yang bergurau di kelas, bukan karena dia ingin mengubah profesi dari seorang guru menjadi pelawak. Gurauan guru harus disadari dalam rangka (a) menciptakan suasana kelas agar tidak tegang, (b) untuk mempermudah masuknya informasi dari memori jangka pendek ke memori jangka panjang, (c) membuat persepsi siswa bahwa guru memang pantas disebut guru oleh siswa, dan (d) tujuan untuk mencapai kompetensi belajar.

Dalam proses pembelajaran di kelas, guru harus dapat menyeimbangkan kata-kata verbal dan nonverbal agar kompetensi pembelajar dapat berkembang dengan baik. Dalam hal bahasa verbal, pilihan bunyi, struktur kalimat, pilihan kata, dan makna kata harus dipertimbangkan dengan baik. Begitu juga, penggunaan bahasa nonverbal. Penggunaan BN dinamis, seperti anggukan kepala, gelengan kepala, gerakan tangan, gerakan jari, kerdipan mata, jarak bicara, harus dipikirkan oleh guru. Begitu juga BN statis, seperti potongan rambut, raut muka, model pakaian, make up harus disesuaikan dengan situasi pembelajaran . Dengan demikian, seperti sudah diuraikan di atas bahwa seorang guru ibarat sebagai seorang aktor, juga berperan sebagai penulis skenario, dan sekaligus berperan sebagai sutradara yang mengatur jalannya pembelajaran. 
Agar pembelajaran BN dapat diintegrasikan dengan bahasa verbal dalam pembelajaran BIPA, kesalahan-kesalahan dalam belajar bahasa tidak harus dijadikan permasalahan. Dulay (1982) menyatakan "You can't learn without goofing" (Anda tidak dapat belajar tanpa kesalahan). Yang perlu ditekankan dalam proses belajar bahasa adalah bahwa strategi belajar harus memungkinkan pembelajar mampu belajar (focus on the learners). Agar situasi beajar seperti dapat tercipta dengan baik, seorang guru dapat diibaratkan sebagai seperti seorang komposer, dapat menyatukan unsur-unsur kalimat dengan cara membuat maknanya sejelas mungkin agar mudah diingat (Karim \& Sotoudehnama, 2017). Dalam kaitannya dengan proses pemerolehan dan pembelajaran bahasa, setiap pembelajar memiliki strategi belajar sendiri-sendiri. Meskipun teknologi sudah berkembang pesat, tidak semua anak dapat diseragamkan strategi belajarnya menggunakan teknologi yang berkembang saat sekarang. Setiap orang memiliki karakteristik sendiri-sendiri yang berkaitan dengan proses pemerolehan bahasa kedua atau bahasa asing, seperti faktor bakat, perkembangan kognitif, motivasi, kondisi emosi, dan lain-lain (Barnwell, O’Malley, \& Chamot, 2006). Di antara faktor-faktor tersebut, fokus subbab ini adalah strategi pembelajaran.

Seorang guru sebagai konstruktor maksudnya guru dapat membangun berbagai hal dengan menempatkannya melalui berbagai cara. Konstruktor dapat membuat konstruksi yang menjadikan siswa dapat menerima kehadiran guru di dalam kelas. Misalnya, guru mengajarkan dengan metode tatabahasa, guru mengontruk struktur tata bahasa. Jika elemen struktur diatur dengan benar, hal itu akan dapat diterima secara akal sehat bagi peserta didik. Jika "guru sebagai konstruktor" ketika itu guru berusaha untuk menyatukan bagian-bagian yang berbeda dari unsur-unsur tata bahasa dengan BN akan dapat memberikan keaktifan kepada siswa. Misalnya, ketika guru ingin mengajarkan unsur-unsur pidato, dia menunjukkan tangannya dan menamai setiap jarinya sebagai bagian yang pasti dari sebuah kalimat, kemudian dia meminta para siswa untuk mengganti setiap bagian itu ketika guru memerintahkan. Metode pengajaran tata bahasa ini mengingatkan siswa tentang struktur kalimat yang benar pada waktu itu atau waktu-waktu lain berikutnya. Beberapa siswa mengamati kontak mata sebagai alat untuk memahami hal-hal yang mungkin tidak dapat dipahami untuk mereka jika diucapkan hanya secara verbal.

Guru juga ibarat cermin, seorang guru tidak mengatakan apa pun kepada siapa pun di kelas tetapi pada saat yang sama tindakan guru memiliki banyak hal untuk disebutkan secara tidak langsung. Cermin tidak mengatakan tentang poin positif atau negatif kita secara langsung tetapi pada saat yang sama memberi tahu kita tentang perbuatan baik kita dan orang-orang yang harus diperbaiki atau ditingkatkan. Guru yang menggunakan ekspresi wajah mereka bisa seperti cermin bagi siswa. Melalui ekspresinya, guru ditangkap siswa seperti telah memberi tahu bahwa dia baik atau tidak baik di kelas. Siswa menyatakan, ekspresi wajah guruku seperti cermin yang refleksinya membuatku sadar akan perilakuku di kelas. Ekspresi guru menunjukkan pentingnya ekspresi wajah sebagai umpan balik bagi siswa. Bahkan senyum kecil guru atau kerutan yang lemah dapat memengaruhi kecenderungan siswa terhadap guru di kelas. Efek dari ekspresi wajah guru pada siswa semacam ini, tergantung pada sensitivitas siswa. Dapat disimpulkan bahwa wajah guru berfungsi sebagai cermin, yang mencerminkan perbuatan siswa di kelas.

Guru ibarat seorang konduktor dalam orkestra musik. Seorang konduktor mencoba mengoordinasikan setiap anggota orkestra satu dengan yang lain untuk menjaga harmoni musik. Jika masing-masing musisi bermain terlepas dari yang lain, hasilnya akan menjadi suara sumbang. Guru sebagai konduktor dapat menjaga harmoni dalam kegiatan kelas dan mengendalikan perilaku siswa. Terkadang guru menggunakan ekspresi wajah untuk mengendalikan siswa dan menjaga disiplin kelas.

Berdasarkan teori Karim \& Sotoudehnama (2017) di atas, kreativitas seorang guru harus dibenahi agar mereka mampu menciptakan atmosfir belajar di kelas sehingga pembelajar tumbuh minat kuat untuk menguasai bahasa asing yang ingin dikuasai. Hal yang perlu diperhatikan dalam belajar, seorang pembelajar ada yang suka belajar dengan model metakognitif dan ada yang suka model kognitif. Belajar dengan strategi metakogitif, pembelajar mulai merancang pengorganisasian, penilaian, dan perencanaan. Sementara pembelajar lain menerapkan strategi kognitif, pembelajar mulai dari menganalisis, menalar, mentransfer informasi, mencatat, dan meringkas. Kedua model strategi tersebut harus disadari oleh guru agar pembelajaran di kelas dapat variatif sehingga setiap pembelajar dapat berkembang kemampuan berbahasanya.

\section{Simpulan}

Berdasarkan hasil kajian teori di atas, dapat disimpulkan beberapa hal sebagai berikut. Pertama, berkomunikasi bahasa lisan ternyata penggunaan bahasa nonverbal jauh lebih banyak dibandingkan penggunaan bahasa verbal. Bahasa nonverbal yang sering menyertai bahasa verbal dapat dibedakan 
menjadi dua, yaitu bahasa nonverbal dinamis dan bahasa nonverbal statis. Bahasa nonverbal dinamis, seperti gelengan/anggukan kepala, kerdipan/kerlingan mata, lambaian tangan, gerakan jari, gerakan siku, dll. Bahasa nonverbal statis, seperti raut muka, warna kulit, warna rambut, bentuk bibir, bentuk bola mata, postur tubuh, dll. Di samping itu, bahasa nonverbal statis dapat pula berupa status sosial dalam masyarakat, seperti asal keturunan (priyayi luhur, priyayi cilik, rakyat biasa), tingkat pendidikan (pendidikan tinggi, pendidikan menengah, dan pendidikan rendah), tingkat kecerdasan (esem Bupati, senyum mantra, dan dhupak bujang), serta pemilihan jodoh (bobot, bibit, Bebet).

Kedua, Pembelajaran BN yang diitegrasikan dengan bahasa verbal berdasarkan pendekatan pragmatik perlu mendapat perhatian dan dicari model pengintegrasiannya. Karena selama ini, pembelajaran bahasa pada umumnya, dan juga untuk pembelajar BIPA hanya terbatas pada pembelajaran bahasa verbal saja. Padahal, pembelajar BIPA tidak sekedar dapat berbahasa verbal tetapi mereka juga dapat berkomunikasi dengan memahami latar belakang budaya masyarakat penuturnya.

Ketiga, pragmatik edukasional pada hakitatnya adalah pembelajaran bahasa berdasarkan pendekatan pragmatik. Pendekatan pragmatik dimaksudkan untuk melengkapi pembelajaran bahasa yang semula hanya memperhatikan aspek intralingual ditambah dengan melibatkan aspek ekstralingual berupa konteks. Konteks yang dimaksud mencakup konteks sosial, sosietal, situasi, dan budaya. Hal ini berkaitan dengan kompetensi pragmatik. Dengan demikian, pemakaian bahasa yang baik, benar, santun, dan akurat adalah pemakaian bahasa yang diungkapkan pembelajar BIPA yang memahami aspek konteks dan menguasai kompetensi pragmatik.

Keempat, pembelajaran BIPA dengan mengintegrasikan bahasa verbal dan nonverbal biasanya dilakukan dalam situasi formal di kelas. Kajian ini sejalan dengan pendapat Krashen bahwa pengusaan bahasa kedua/bahasa asing biasa terjadi dalam situasi formal. Meskipun teori Krashen sudah begitu berpengaruh, salah satu aspek penting yang belum diajarkan adalah proses pembelajaran BN. Padahal, penggunaan $\mathrm{BN}$ dalam komunikasi lisan mencapai sekitar 93\% dari keseluruhan pemakaian bahasa verbal lisan (Lapakko, 2007). Namun, pembelajaran BN yang dilakukan di dalam kelas tetap menyertai bahasa verbal lisan.

Kelima, salah satu strategi pembelajaran BIPA perlu memperhatikan teori pembelajaran bahasa. Beberapa aspek yang perlu diperhatikan antara lain bahwa seorang guru diibaratkan sebagai komposer, konstruktor, cermin/reflektor, dan conductor. Meskipun demikian, guru BIPA harus memperhatikan latar belakang pembelajar dan suasana kelas tempat mereka belajar.

\section{Ucapan Terima Kasih}

Terima kasih penulis ucapkan kepada tim editorial Jurnal Bahasa Indonesia bagi Penutur Asing (JBIPA) yang telah membantu penulis selama proses penerbitan artikel penelitian ini. 


\section{Referensi}

Abrahamsen, E. J., Ahern, B. J., Parente, E. J., Aitken, M. R., Southwood, L. L., Ross, B. M., ... Hung, T. (2015). Preliminary Investigation of the Treatment of Equine Medial Femoral Condylar Subchondral Cystic Lesions With a Transcondylar Screw. Veterinary Surgery. https://doi.org/10.1111/j.1532-950X.2014.12199.x

Barnwell, D., O’Malley, J. M., \& Chamot, A. U. (2006). Learning Strategies in Second Language Acquisition. Language, 67(2), 416. https://doi.org/10.2307/415153

Botting, N. (2005). Non-verbal cognitive development and language impairment. Journal of Child Psychology and Psychiatry and Allied Disciplines. https://doi.org/10.1111/j.14697610.2004.00355.x

Deda, N. (2013). The role of Pragmatics in English Language Teaching. Pragmatic Competence. Academic Journal of Interdisciplinary Studies. https://doi.org/10.5901/ajis.2012.v2n4p63

Dulay, Heidi; Marina Burt and Stephen Krashen. 1982. Language Two. New York: Oxfort University Press.

Fandohan, A. B., Chadare, F. J., Gouwakinnou, G. N., Tovissode, C. F., Bonou, A., Djonlonkou, S. F. B., ... Bosu, P. P. (2015). S a m p l e. Food Chemistry. https://doi.org/10.1016/B9780-12-396959-0.00001-X

Franco, C. P., \& Galvis, H. A. (2014). The Role of Situational Context and Linguistic Context when Testing EFL Vocabulary Knowledgde in a Language Teacher Education Program: A Preliminary Approach. Colombian Applied Linguistics Journal, 15(1), 85. https://doi.org/10.14483/udistrital.jour.calj.2013.1.a06

$\mathrm{Hu}, \mathrm{X}$. (2014). Context: from static to dynamic. 2(2), 127-133. https://doi.org/10.11648/j.ijl1.20140202.21

Karim, A. H., \& Sotoudehnama, E. (2017). A Qualitative Study on Teacher's Nonverbal Communication and Iranian EFL Learners 'Perception of Language Learning 1. 1(1). https://doi.org/10.22051/lghor.2017.13392.1044

Krashen, Stephen. (2013). Second Language Learning and Teachng. At-Ta'dib, 8(2). https://doi.org/10.21111/at-tadib.v8i2.504

Krauss, R. M., Chen, Y., \& Chawla, P. (1996). Nonverbal Behavior and Nonverbal Communication: What do Conversational Hand Gestures Tell Us? Advances in Experimental Social Psychology. https://doi.org/10.1016/S0065-2601(08)60241-5

Lapakko, D. (2007). Communication is 93\% Nonverbal: An Urban Legend Proliferates. Communication and Theater Association of Minnesota Journal, 34, 7-19. Retrieved from http://cornerstone.lib.mnsu.edu/ctamj

Negi, J. S. (1970). The Role of Teachers' Non-Verbal Communication in ELT Classroom. Journal of NELTA, 1(1), 101-110. https://doi.org/10.3126/nelta.v14i1.3096

Pranowo. (2018). Basa Jawa Krama Alus lan Santun. Yogyakarta: Dinas Kebudayaan Propinsi DIY.

Rahardi, K. (2009). Sosiopragmatik. Yogyakarta: PT Gelora Aksara Pratama.

Song, L. (2011). The Role of Context in Discourse Analysis. Journal of Language Teaching and Research. https://doi.org/10.4304/jltr.1.6.876-879

Takkaç Tulgar, A. (2018). The Role of Pragmatic Competence in Foreign Language Education. Turkish Online Journal of English Language Teaching. https://doi.org/10.32959/tojelt.229304

Tuma, J. M., \& Pratt, J. M. (1982). Clinical child psychology practice and training: A Zhou, H. (2009). Body language in Business Negotiation. International Journal of Business and Management, 3(2), 90-96. https://doi.org/10.5539/ijbm.v3n2p90 